\title{
Correction of the Codependent Behavior: Propose a Psychological Program
}

\author{
Yekaterina Raklova \\ Candidate of Psychological Science, Innovative University of Eurasia, Kazakhstan
}

Copyright $@ 2019$ by authors, all rights reserved. Authors agree that this article remains permanently open access under the terms of the Creative Commons Attribution License 4.0 International License

\begin{abstract}
The problem of codependence, which occupies an important place in the research of individual human features, is reviewed in this article. Codependency is one of the most complex and actively investigated problems. It is explained by its exceptional role in the formation of personality individual uniqueness, its role in a person's interaction with the environment as well as its close relationship with his/her mental and physical health. In the process of theoretical and practical development of the problem, the basic principles of psycho-pedagogical correction approaches were formulated, the necessity of using a number of means, influencing on the dynamics of codependent personality states was founded. The choice of specific tools to work with codependent personality states was tested in the psychological and social centers. During the experiment the programme of codependent personality states correction has been elaborated and conducted. This programme, which considers the data, got during the diagnostic research, allowed to decrease the level of psycho-emotional tension, to develop the ability to self-regulate behavior and it contributed to enhancing the overall activity of codependent women. The scientific novelty of the research lies in the fact that for the first time a systematic approach to the correction of codependent personality states was considered: the factors of adaptive behavior of a person, after participating in a correction program, were identified; the relationship between the system of psychological means and the adaptability of behavior of codependent women was established; a model of psychological support for codependent women was developed.
\end{abstract}

Keywords Codependency, Addiction of Relations, Toxic Emotions, Family Problems, Codependency Correction

\section{Introduction}

In recent decades, the modern science of psychology, sociology, pedagogy and medicine is increasingly focusing on one of the urgent problems of modern anthropology the problem of codependency. Many researchers point directly to the exceptional importance of this phenomenon in the life of both the individual and certain social groups.

Recently, in our country psychology interest in the problem of codependency has increased significantly. If before the mid-90s of the twentieth century our country's researches in this area was rather fragmented, and their number was small, then in recent years here have appeared the publication of a series of monographs, theses researches, articles in specialized journals devoted to this issue. According to E.A. Zaluchenkova (1995), over the past forty years, more than five thousand articles and monographs devoted to various aspects of anxiety problems' analysis, as one of the main codependency characteristics, were published in psychology. The researchers have been studying this issue from different points, both as motivation and as an emotional state, as well as a property and a personality trait etc. Nevertheless, there are still many unknown and areas waiting to be explored [1].

C. P. Korolenko, N. V. Dmitrieva (2003) define codependency as addiction of relationships. According to them, "codependent people" use relationships with another person as chemical or non-chemical addicts use addictive agent.

M. Beattie (1997) brings to the concept of "codependency" the following contents: a constant concentration of thought on someone or something, emotional dependence, sometimes physical from a person. Often, this addiction to a person becomes pathological, affecting all other relationships.

The following authors have contributed to the elaboration of the problem (E. Smith, 1991; V. Satir, 2000; H. Cloud, 1999; N. Ivanets 1988; I.G. Shvets, 2001; M. Beattie, 1997; A. Myager, 1979; C.P. Korolenko, N. V. Dmitrieva, 2001; E. G. Eydemiller, V. V. Yustitsky, 1999).

Relevance and significance. Despite the fact that in modern psychology codependent personality states are subjected to rigorous and comprehensive study, there are 
still many unexplored issues. So far, in particular, the issue of 'codependency' definition is not revealed due to a wide range of interests of the researchers involved in the study of this phenomenon. Moreover, there are explicit unresolved contradictions between:

- increasing levels of neuroticism of society in general, increased levels of codependent states of the wives of men, who have problems with alcohol, and the need to develop a mentally and physically healthy person;

- between the issues of forming a favorable psychological climate in the family and a high level of codependence of individual members, preventing the fulfillment of this task;

- between the available symptomatic approaches to overcome codependency and the need for its correction using personality oriented psychological techniques.

According to one of the most common foreign addictology concepts of alcoholism psychogenesis (C. Hedde, 1985), alcoholism is not considered as an individual pathology, but as a result of interaction between family members or as a part of the functioning of the family structure aimed at maintaining family homeostasis. According to the author, alcohol plays a central role in family life - adversely affects the mental state of others, which ultimately leads to deterioration and degradation in the physical, mental, emotional and spiritual spheres.

The most important issue today is the liberation of the individual from the codependent states. V. Moskalenko identifies the following factors of codependency: living with a person suffering from any addiction, lack of social support in the entourage, the necessity to overcome the difficulties [18].

According to V. Moskalenko, the codependent condition is characterized by: 1) delusion, denial, self-deception; 2) compulsions (unconscious irrational behavior, which people may regret, but still acts as if they are driven by an unseen inner strength; 3) frozen feelings 4) low self-assessment; 5) health problems associated with stress.

G. Klaud (1999) investigated the codependency as a basic phenomenon, understanding of which is necessary for the analysis of emotional and psychological disorders. codependent personality states, as Mr. Cloud noted, is a fundamental phenomenon and underlies neurosis [22]. The notion of "codependency" is still unknown for a common person. According to E. Smith, co-dependents come from families, with substance dependence or abuse: emotional, intellectual, physical violence or sexual abuse. Both dependency and codependency are long sufferings, leading to deformation of the spiritual sphere. E. Smith believes that in a codependent deformation is expressed in the fact that they hate instead of love, lose faith in everyone but himself, even though they do not their own healthy impulse, feeling a burning sense of jealousy, envy and despair.

Thus, codependent people make outwardly impression as super-responsible, but they are equally irresponsible for their condition, for their needs, for their health and are not able to manage with their parental responsibilities in a proper way [2].

E. Berne (1992) stated that the basis of life plan is largely formed under the influence of parents' relation to the child and it occurs before his/her birth.

Studying codependency at different stages of childhood and adulthood is important for understanding the age patterns of human emotional development, for the formation of its emotional and personality structures. It is codependency, as many researchers noticed (V. D. Moskalenko, G. M. Rozhnova, 1997, 1996; C. P. Korolenkao, N. V. Dmitrieva, 2001; M. Beattie, 1986, etc.) which is based on the number of psychological difficulties of childhood, including many disorders in development.

Insufficient knowledge of the issue and its complexity is that codependency, as a psychological climate, is an addictive factor.

L. D. Miroshnichenko (2001) defines this phenomenon as a condition of anxiety, experienced by a person without realising its source; it is the condition of "free floating" danger and uncertainty [20].

V. D. Moskalenko (1994), defining the essence of the phenomenon, pointed out that "co-dependency is a tendency of a person to experience anxiety, and one of the main indicators of individual differences and personal distress symptoms in the interaction between a person and the environment" [18].

In our opinion, codependency is a painful condition for anyone suffering from it. Codependent members of a family use the rules and forms of relationships that keep the family in a dysfunctional state. Codependency is a risk factor for recurrence of dependence, occurrence of various disorders in the following generation, in the first place - the risk of the same dependence. Codependency is a basis for psychosomatic disorders and depression.

\section{Materials and Methods}

Among the studied problems of codependency, the problem of diagnosing of codependent personality states is very relevant and meaningful for researchers and practicing psychologists.

Codependent personality states affects all areas of the individual psyche: affective-emotional, communicative, moral-volitional, and cognitive. The characteristic features caused are the development of motivation, self-awareness and self-esteem.

The methodological basis of the study is represented by the combination of the following methods and techniques:

1. The method of content analysis of documents.

2. The method of observation.

3. The method of experimental research.

4. Method of psychodiagnostics using methods: individual typological questionnaire (ITQ); 
Interpersonal Relationship Diagnostics (IRD); an adapted version of MMPI, "Mini-cartoon" (F. B. Berezin and M. P. Miroshnikov.); TAT (thematic apperception test) by L. N. Sobchik, methodology of sentence completion by D. Saks; methods of personal assessment (Q-sorting); Spielberger and Khanin scale for reactive and personal anxiety.

5. While processing the data the methods of mathematical statistics were used. The calculations were performed by using the Microsoft Visual Basik 5 computer software package and STATISTICA (6.0) software, Microsoft Excel XP statistical software package and data interpretation using the criteria: $(\mathrm{t}$ Student's criterion, Spearman's ordinal correlation coefficient (p), correlation analysis, including analysis of changes obtained in the experimental and control groups). Theoretical methods, which include the study and analysis of philosophical, psychological and pedagogical literature of the researched problem, as well as synthesis, comparison, systematization.

6. Empirical, involving a formative experiment, testing with the help of the tasks to identify the level of the codependent state of the individual, and also by using the computer technique "Communication Style", scaling, questioning, and analysis of the activity products.

7. Interpretative-descriptive includes quantitative methods (correlation analysis), qualitative analysis of the obtained data and methods of graphical presentation of results.

Properly conducted diagnostics allows a specialist to not only adequately prepare an inference, but also to orient in the tendencies and methods of psychological help to people, suffering from one or other symptoms of codependency. That is why among the methods of psychological diagnosis, the methods for the codependency study occupy a special place $[3,4]$.

Among the foreign and local researchers studying the development of this problem, there are following authors: D. W. Goodwin, 1988; P. T. Potter-Efron, 1989; S. R. Covey, 1989; S. P. Thoele, 1991; A. W. Schaef, 1986; E. W. Smith, 1991; L. K. Sibley, 1999; C. S. Korolenko, N. V. Dmitrieva, 2010; V. D. Moskalenko, 1994, 2000; I. G. Shvets, 2001; M. Beatty: 1997, T. A. Shabanov, 1998; V. K. Myager, E. G. Eidemiller, 1980; S. I. Chaeva, 1992; A. I. Sakharov etc. [13,14,15,16,21].

Psychodiagnostic battery application to build codependent people's personal identity portrait helped to identify the individual characteristics of the psyche, to determine the degree of its intensity, to predict its behavior in complex contingencies. Below there is a description of the techniques constituting psychodiagnostic battery.

Individual typological questionnaire (ITQ), which helps to identify major trends and style of interpersonal behavior. A new psychological test identifies individual-typological features and evaluates the degree of adaptation of a specific person, including at the varying degrees of the evidence of stress state and in borderline neurotic disorders.

Method of Interpersonal Relationship Diagnostics (IRD) and technique created by T. Leary, G. Leforzh, R. Sazhek in 1954. This method is designed to study the person's views of himself and the ideal «I» and also to explore the relationships in small groups. This technique allows to reveal the predominant type of attitudes to people, self-assessment and mutual assessment.

The method "The Sentence Completion Test" has been used in experimental psychological practice for a long time. There are many variants of the method. This option is designed by Sacks and Levy. It includes 60 unfinished sentences, which can be divided into 15 groups and characterize in varying degrees, the system of relations of the subject in the family, his/her attitude to both higher rank representatives and subordinates.

Mini-cartoon questionnaire (shortened version of the Minnesota multidimensional personality inventory MMPI) was proposed by American psychologists in the 40-50s. Adaptation was carried out in the USSR in the 60s by F.B. Berezin and M.P. Miroshnikov.

Method of Personal Assessment (Q-sort). Q-sorting technique has been designed to explore a person's view of himself. W. Stephenson developed it in 1958. The method allows to determinate six basic tendencies of human behavior in the real group: dependence, independence, sociability, unsociability, the adoption of the "struggle" and the avoidance of the "struggle".

Thematic Apperception Test (TAT). A modified version of the test developed by H. Murray and adapted to in the Russian translation by L.Y. Sobchik, is a battery of eight pictures. The pictures show various options for interaction and behavior of dyads (1, 3, 4, 6, 8th position) and triads (positions 2,5,7). When an examiner is browsing the test scene pictures, he has a vision of everyday situations on the basis of associative links, past experiences, beliefs, attitudes, interests, desires, and general education.

Spielberger and Khanin scale for reactive and personal anxiety, including its shortened version (D. Y. Raigorodskii, 1998), which was used for retesting. This test method is a reliable and informative way of self-assessment level of anxiety.

LSC (level of subjective control) is a questionnaire by Rotter. The questionnaire diagnoses localization of control over significant events. It is based on the distinction between two loci of control - internal and external - and, accordingly, two types of people - interns and externs.

For diagnosis and successive evaluation of the effectiveness of codependency correction, we used dependent personality disorder criteria (F 60.7):

1. shifting of routine problems' solutions to others;

2. lack of willingness to assert reasonable demands to people, on whom a person is depended;

3. discomfort at being alone because of excessive fear to make independent decisions; 
4. concerning of occasion that the closest people can leave him and as a result he will be left to himself;

5. limited ability to make everyday decisions without some advice and approval of others;

6. subordination of own needs to the needs of others.

For diagnosis of dependent personality disorder there must be established at least four of the six symptoms. Dependent personality disorder criteria were used by us to identify codependent personality states and to evaluate the effectiveness of corrective work.

We distinguish three levels of codependency (low, intermediate, high):

1. The low level is characterized by a feeling of growing troubles, anxiety. Family members lose their joy, carelessness, more experienced bitterness, resentment, irritation, anger, spite (toxic emotions).

2. The intermediate level is characterized by denial of toxic emotions, concentration of all attention on dependent, tolerance of the behavior, the sense of one's responsibility for all the family problems, more frequent memory lapses, loss of control over one's life and the life of a dependent person; experience of guilt and shame, the emergence of anger; increase use of alcohol by a dependent; feelings of remorse and stress, adapting to everyday inconveniences, concentration on all actions of dependent, the desire to isolate him, the appearance of distraction; disintegration of the family, the feeling of self-defeat, the emergence of a critically low self-assessment.

3. The high level is characterized by the use of negative emotions. Characterized by complete loss of self-assessment, loss of tolerance to a dependant; spiritual degradation, the appearance of tremor, anxiety, the emergence of severe anxiety, depression. Levels of malnutrition can lead to madness and death or treatment and rehabilitation of the life balance.

At the stage of the pilot study and formative experiment, we used: individual typological questionnaire (ITQ); Interpersonal Relationship Diagnostics (IRD); an adapted version of MMPI, "Mini-cartoon” (F.B. Berezin and M.P. Miroshnikov.); TAT (thematic apperception test) by L.N. Sobchik, methodology of sentence completion by D. Saks; methods of personal assessment (Q-sorting); Spielberger and Khanin scale for reactive and personal anxiety.

To identify the correlation of codependent personality states and personal characteristics of the individual, we used the method of Interpersonal Relationship Diagnostics (IRD). This method is a set of concise characteristics, by which the subject first evaluates himself, his actual "I" at the time of survey. After that he fills up the grid of record sheet, and the points on eight variants of interpersonal interaction are counted. For this they use a key, with the help of which the blocks of 16 numbers, forming 8 octants, are worked out. Interpretation of the IRD data should mainly focus on the prevalence of some indicators over the others.
For the same purposes, we use a multi-personality inventory MMPI. "Mini cartoon" consists of 11 scales, three of which are appraisal, the other eight are the basic scales and assess personality traits in terms of hypochondria, depression, hysteria, psychopathic, paranoid, psych asthenia, schizoid, hypomania. Before the construction of a personality profile, pre-need "raw" scores on the basic scales 1,4,7,8,9 are transferred into conditional scores, i.e. adjusted in accordance with the value of the rating scale $\mathrm{K}$. The transfer of «raw» points in the conditional is done by the formulae:

$$
\text { CS A } 1=0.5 \mathrm{~K} ; \mathrm{CS} 4 \mathrm{~A} 4=0.4 \mathrm{~K} ; \mathrm{CS} 7=\mathrm{A} 7+\mathrm{K} \text {; }
$$

$\mathrm{CS} 8=\mathrm{A} 8+\mathrm{K} ; \mathrm{CS} 9$ A9 $=0.2 \mathrm{~K}$,

where CS- conditional scores on basic scale 1, A1- base scale raw scores, $\mathrm{K}$-value of $\mathrm{K}$ grading scale, etc. (A.V. Batarshev, 1999, p.106).

In the study of group psychological facilities of correction of codependency conditions of personality, we identified the following facilities described in psychological and pedagogical literature and applied in psychological practice:

- $\quad$ group psychotherapy (K. Rogers, K. Rudest am, A. Freud and others);

- $\quad$ socio-psychological training (Y. N. Emelyanov, E. U. Brel, L. F. Ann, O.R. Arnold, T. Y. Artyuhova, S. A. Badmaev, O. V. Frolova, etc.);

- communicative activities (B. G. Ananiev, K. A. Abulkhanova-Slavskaya, A. A. Bodalev, A. M. Prihojan, V. I. Kobrin, R. A. Maximova);

- joint activities, including creative ones (B.G. Ananiev, K. A. Abulkhanova-Slavskaya, M. I. Lisina, S. A. Vodyaha, I. V. Vachkov, I.P. Ivanov, O. S. Gazman, N. P. Anikeeva, etc.);

- $\quad$ playing activity (L. A. Petrovskya, D.B. El'konin, A. M. Prihojan, L. M. Kostin, M. I. Lisina, N. P. Anikeeva, M. A. Panfilova, T. M. Orlova, E. Y. Brel, O.V. Tapilina, N. Y. Bezborodova etc.).

In the process of assisting we had to take into account both the features of the personal growth programme "Manage your life!" (on the basis of which this work was carried out), and the conditions in which it was carried out. Thus, we decided to apply a group of facilities, united by certain logic and complementary moments for the codependency of correction. At the same time, according to the conclusions of the authors who have studied and tested these tools, they have a high efficiency.

By such means we assigned:

I. Verbal: socio-psychological training; sociodrama (Transactional discussion); a family photo;

II. Nonverbal: a family sculpture, family choreography, a role-playing card game.

These means were used for background correction of collaboration group and individual work with co-dependent wives whose husbands suffer from addiction. In our opinion, this activity is a factor when the specified 
means of correction not only simply harmoniously supplement each other, but have higher efficiency in the decrease of the level of codependent personality states rather than in usual conditions.

\section{Results}

Detecting the correlation between codependent personality states and means of psychological correction allowed us to hypothesize about the causal relationship between these two variables. In order to test this hypothesis, the pilot study and the third phase of experiment were held. The psychological experiment was conducted on the basis of the Republican Scientific-Practical Centre for Medical-Social Problems of Drug Abuse in Pavlodar and psychological center "Hermes" of Innovative University of Eurasia. The study involved 347 codependent women aged 25-45, having husbands with alcohol problems. The experimental group consisted of 189 people and the control group - 158 people. The groups were characterized by the same sex, age, education and professional features (Table 1).

Table 1. The composition of the experimental and control groups (\%)

\begin{tabular}{|c|c|c|}
\hline group & Experimental & Control \\
\hline sex & woman - 189 & woman 158 \\
\hline age & $25-45$ y.o. & $25-45$ y.o \\
\hline Education: & & \\
higher & 38 & 36 \\
secondary-technical & 26 & 24 \\
secondary-special & 20 & 22 \\
secondary & 16 & 18 \\
incomplete secondary & - & - \\
\hline Professional similarity: & & 55 \\
"Technicians" & 56 & 20 \\
"Humanitarians" & 23 & 25 \\
others & 21 & \\
\hline
\end{tabular}

We conducted an experiment with preliminary and final psychodiagnostic test in experimental and control groups. As a main criterion, means of correction of codependent personality states were selected. The obtained data were processed by the methods of mathematical statistics (tStudent test, Spearman ordinal correlation coefficient (p), correlation analysis, including an analysis of the changes produced in the experimental and control groups). The results of the experiment showed the effectiveness of correctional programs, including the verbal and nonverbal means.

1. Analysis of existing knowledge about the nature of codependency and its requirements for mental peculiarities of a person allowed us to formulate a definition of the essential characteristics of the subject of the study. Codependent personality states is a dynamic characteristic, as a result of which its correction is possible. Under certain conditions, it is realistic to achieve a reduction in the level of codependent personality states.
2. Analysis of the problems of codependency, conducted in order to identify ways of correcting the dependent states of a person, made it possible to establish that codependency can be reduced with the help of such psychological means as verbal ("Family Photo", "Sociodrama", socio-psychological training) and non-verbal means ("Family Sculpture", "Family Choreography", the technique of "Role card game")

3. Codependent personality states have a positive dynamic in case of timely psychological correction. The main means contributing to the effective psychological correction of socially codependent personality states are verbal and non-verbal means.

4. Timely and systematic use of means of correction of socially codependent personality states contributes to the awareness of one's own problems, weakening of the need to control others, sharing feelings with others, creating motivation for change, developing optimism, reducing fears, getting rid of guilt, emerging of new interests, spiritual reappraisal, self-improvement , the development of creative potential.

Causes of codependency can have two bases.

1. Natural basis: psycho-physiological characteristics of the organism: type of nervous system, genetic predisposition, nature of sensitivity. The process of prenatal development and childbirth is significant as well.

2. Social basis: social factors revealed at the macro - and micro-social level. Social factors include the type of family, microclimate in the family, in kindergarten, school community, features of the parental position.

We assume that:

1. Dependence meets the criteria for pathological personality development.

2. Socially dependent behavior of a person is determined by the experience of childhood psychodramas (distortion of feelings, tendency to denial, diseases caused by stress, damage to the spiritual sphere), subjectively disintegrating an adequate perception of oneself and the environment.

3. External reference of codependent wives is manifested in the absence of borders. They do not know where their personality ends and where the identity of another person begins.

4. Society stimulates the development of codependency, "loading" codependent wives with the slogan: "You must endure and suffer".

5. Codepages is a more severe form of addiction than addiction to a particular activity or agent.

6. The basis of any addiction is codependency, which provokes the development of other addictions.

Using the arithmetic mean, we identified the degree of preference for each of the factors. The data we obtained in the diagram were distributed as follows: 


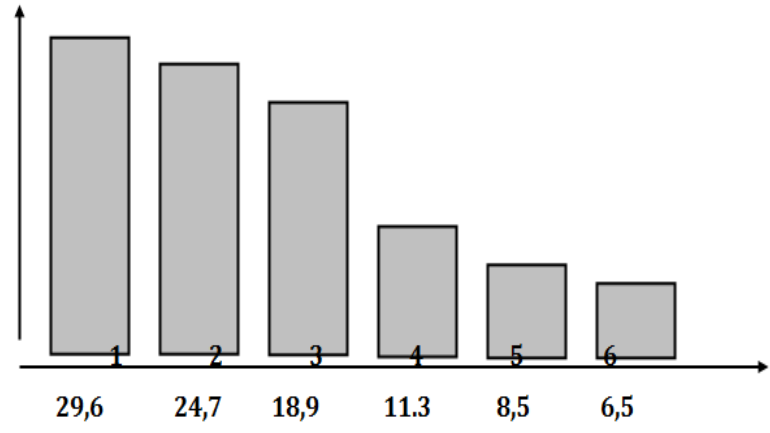

Figure 1. The distribution of factors affecting the decrease in codependency

Note:

1. socio-psychological training;

2. family sculpture, family choreography.
3. work with verbal and non-verbal signals proceeding from ego states (a bad parent, a caring parent, an adult, a little professor, a natural child), a family photo.

4. sociodrama (transactional discussion);

5. a role card game;

6. clubs of interest.

Indicators of verbal and nonverbal means of codependency correction represent personality reorientation towards internal locus of control, gain self-sufficiency, autonomy and spontaneity of identity (Table 2).

The suggested hypothesis was not only confirmed experimentally, but was also rechecked, using the Student t-test, which confirms the high reliability of the data. The coefficient calculated by this criterion has a high degree of reliability (Table 3).

Table 2. Evaluation of the effectiveness of the correctional program

\begin{tabular}{|c|c|c|c|c|}
\hline \multirow{2}{*}{ Groups } & \multicolumn{2}{|c|}{ Experimental group $(\mathrm{n}=13)$} & \multicolumn{2}{|c|}{ Control group ( $\mathrm{n}=16)$} \\
\hline & before psychocorrection & after psychocorrection & before & after \\
\hline $\begin{array}{l}\text { codependent women } \\
25 \text { - } 30 \text { years old }\end{array}$ & $1,27 \pm 0,20^{* *}$ & $1,14 \pm 0,15^{* *}$ & $1,19 \pm 0,13^{*}$ & $1,17 \pm 0,12^{*}$ \\
\hline \multirow{3}{*}{$\begin{array}{l}\text { codependent women } \\
31 \text { - } 39 \text { years old }\end{array}$} & \multicolumn{2}{|c|}{$\begin{array}{c}\text { Experimental group } \\
(\mathrm{n}=11)\end{array}$} & \multicolumn{2}{|c|}{$\begin{array}{c}\text { Control group } \\
(\mathrm{n}=27)\end{array}$} \\
\hline & before psychocorrection & after psychocorrection & before & after \\
\hline & $1,26 \pm 0,21$ & $1,13 \pm 0,18$ & $1,23 \pm 0,10$ & $1,21 \pm 0,13$ \\
\hline \multirow{3}{*}{$\begin{array}{l}\text { codependent women } \\
40 \text { - } 45 \text { years old }\end{array}$} & \multicolumn{2}{|c|}{ Experimental group $(\mathrm{n}=12)$} & \multicolumn{2}{|c|}{ Control group $(n=11)$} \\
\hline & before psychocorrection & after psychocorrection & before & after \\
\hline & $1,15 \pm 0,20 *$ & $1,04 \pm 0,23^{*}$ & $1,20 \pm 0,14$ & $1,19 \pm 0,11$ \\
\hline
\end{tabular}

Note:*,** - Statistically significant differences between the groups indicators before and after the impact of psycho-correction $(*-\mathrm{p}<0.05$; ** $\mathrm{p}<0,01)$.

Table 3. Reliability indicators of change in the values of the codependency level before and after the experiment (by Student's t-test).

\begin{tabular}{|c|c|c|c|c|c|}
\hline Denomination & $\begin{array}{l}1 \text { - Average } \\
\text { value } \%\end{array}$ & $\begin{array}{l}\text { 1-Confidence } \\
\text { interval av. \% }\end{array}$ & $\begin{array}{l}2 \text {-Average } \\
\text { value } \%\end{array}$ & $\begin{array}{l}\text { 2- Confidence } \\
\text { interval av. \% }\end{array}$ & $P$ \\
\hline Level of codependency to 0 & 0 & $0<>2.8$ & 0 & $0<>3.2$ & \\
\hline $\begin{array}{c}\text { Level of codependency } \\
\text { to }\{1 \ldots . .<2\}\end{array}$ & 28 & $+/-6.4$ & 30.4 & $+/-7.2$ & \\
\hline $\begin{array}{l}\text { Level of codependency } \\
\text { to }\{2 \ldots . \ldots 3\}\end{array}$ & 34.9 & $+/-6.8$ & 39.2 & $+/-7.6$ & \\
\hline $\begin{array}{c}\text { Level of codependency } \\
\text { to }\{3 \ldots \ldots<4\}\end{array}$ & 37 & $+/-6.9$ & 30.4 & $+/-7.2$ & \\
\hline $\begin{array}{c}\text { Level of codependency } \\
\text { after } 0 .\end{array}$ & 30.2 & $+/-6.5$ & 4.4 & $+/-3.2$ & $<0.01$ \\
\hline $\begin{array}{l}\text { Level of codependency } \\
\text { after }\left\{\begin{array}{ll}1<2\end{array}\right\} \\
\end{array}$ & 47.6 & $+/-7.1$ & 34.2 & $+/-7.4$ & $<0.05$ \\
\hline $\begin{array}{c}\text { Level of codependency } \\
\text { after }\left\{\begin{array}{ll}2<3\end{array}\right\}\end{array}$ & 22.2 & $+/-5.9$ & 37.3 & $+/-7.5$ & $<0.01$ \\
\hline $\begin{array}{l}\text { Level of codependency } \\
\text { after }\{3 .<4\}\end{array}$ & 0 & $0<>2.8$ & 24.1 & $+/-6.7$ & $<0.01$ \\
\hline
\end{tabular}


Table 4. Reliability indicators of change in the values of the codependency level before and after the experiment (by Student's t-test)

\begin{tabular}{|c|c|c|c|c|c|}
\hline Name & $\begin{array}{c}\text { 1- Number of } \\
\text { subjects }\end{array}$ & $\begin{array}{c}\text { 1-average value.1-trust } \\
\text { interval average } \%\end{array}$ & $\begin{array}{c}\text { 2-number of } \\
\text { subjects }\end{array}$ & $\begin{array}{c}\text { 2. average value } \\
\text { 2. trust interval average } \%\end{array}$ & $P$ \\
\hline Positive dynamics & 189 & $87.3+/-4.7$ & 158 & $24.7+/-6.7$ & $<0.01$ \\
\hline Age $\{25 \ldots .<30\}$ & 58 & $93 .\{81.4<>97\}$ & 46 & $17.4+/-11$ & $<0.01$ \\
\hline Age $\{30 \ldots .<35\}$ & 59 & $89.8+/-7.7$ & 35 & $34.3+/-15.7$ & $<0.01$ \\
\hline Age $\{35 \ldots .<40\}$ & 35 & $85.7+/-11.6$ & 33 & $24.2+/-14.6$ & $<0.01$ \\
\hline Age $\{40 \ldots<45\}$ & 30 & $83.3\{64.3<>93.5\}$ & 32 & $18.8+/-13.5$ & $<0.01$ \\
\hline Age $\{45 \ldots .<50\}$ & 4 & $0 \% ? \mathrm{n}<10$ & 12 & $41.7\{14.2<>73.5\}$ & \\
\hline
\end{tabular}

The positive dynamics of the study (age).

The dynamics of getting rid of codependency are more traceable at the age of 25 to 35 . The comprehensive program for the correction of personality dependent states of an individual, developed and conducted during the experiment and taking into account the data obtained during the diagnostic study, has reduced the level of psycho-emotional tensions, developed the ability to self-regulate one's behavior and contributed to enhancing the overall activity of codependent women.

\section{Discussion}

Psychophysiological mechanisms of anxiety and phobic codependency conditions of personality are considered by P. K. Anokhin (1975, 1980), K. V. Sudakov (1987), S. V. Koroleva (2000), A. V. Waldmann (1979), A. O. Prokhorov (1991). The results of these researches suggest that the mechanism of codependency formation is directly linked to an external stimulus. In the presence of the corresponding motivation and the opportunities to satisfy it, there is a functional system of retaliatory behavior. Informational signals are causing directional behavior of the functional system to achieve the desired result. (P. K. Anokhin, 1980; K. V. Sudakov, 1987). Neurodynamic systems, selecting the information function on the basis of generalized past experience and memory. We are interested in the mechanism of derivation and formation of codependency according to the type of origin and fixing of neoplasms in the personality structure, designed by B.C. Becnel (1991). According to the author, at the primary stage, there is a non-equilibrium state - anxiety. At this stage of the anxiety origin, there is a formation of the dynamic reference nucleus consisting of mental processes in which codependency is manifested. With its constant repetition it becomes dominant, which leads to the formation of neoplasms, which in turn lead to fixing of corresponding properties - codependency. At the second stage, codependency is clearly expressed and fixed in a specific activity and behavior of an individual. At the third stage, the formed neoplasm, assuming the character of personality, reproduces by itself the mental state on the basis of which it arose.

C. Hurcom, A. Copello (2000) indicate that the cause of increasing the level of codependent personality states may be the significance of the situation. The more significant the situation is for an individual, the higher the level of codependency is. In its turn, the specifics of codependency depend on personal sense of goals, evaluation of the situation in which a person is being.

In the research by N. G. Artemtseva stated that in a family with a codependent (a drug addict, alcohol addict, workaholic, etc.) relatives' codependence has several functions. On the one hand, it helps the destructive system to keep the balance; on the other hand, it supports its dysfunctional lifestyle which encourages addict's fixation. The family loses its adaptability, disharmonious and manipulative relationships occur. The detailed analysis revels that in such relationships every member has his/her own psychological role, there are some secret rules precisely followed by everyone [25].

Both external and internal motives may lie at the base of the deployment and flow of codependency. Codependent personality states affects all areas of the individual psyche: affective-emotional, communicative, moral-volitional and cognitive.

The development of motivation, self-awareness and self-esteem has their characteristic feature. The researches by M. Beatty, V. Satir, Z. V. Korobkina, A. S. Spivakovskaya, V. I. Garbuzova, G. M. Breslav, V. E. Kagan, E. V. Kucherova, M. L. Yakubovskaya, V. D. Moskalenko, TS. P. Korolenko, N. V. Dmitrieva allow us to draw conclusions that people with a socially codependent personality states belong to risk groups for neurosis, addictive behavior, emotional personality disorders.

Almost all experts related somehow to the study of codependency recognize the significant influence of codependent personality states on the performance and quality of an individual's activities, his emotional state, level of self-esteem, adaptation and somatic health.

His behavioral reactions are inadequate in nature: avoiding the struggle (up to various kinds of "departures": into illness, alcoholism, drug addiction, etc.); aggression, which creates new difficulties for a dependent; hidden forms of behavior, such as theft, lying (sometimes reaching the stages of pathological lies), hidden revenge, etc.

It should be noted that the views of various researchers on the role of codependency are diverse and sometimes highly contradictory. In our work we have covered most of 
them.

\section{Conclusions}

Thus, there was detected a significant change in the level of co-dependence in the experimental group compared to the control. This confirms our hypothesis about possibility of effective application of psychological means to correct the codependent personality states.

There was revealed the connection between indicators of reducing codependent conditions of personality (anxiety, fear, impulsivity, self-centeredness, stubbornness, shame, guilt, hatred, depression, self-destructive behavior, etc.) and verbal and non-verbal means.

The analysis of the mental development and identity formation of codependent wives has revealed the mental states, formed in early childhood, which include: impulsivity, egocentrism, stubbornness, sensitivity, shame, guilt, hatred, depression, self-destructive behavior. This category of examinees has a high level of anxiety, fear, aggression and destructive behavior, depression, cognitive impairment, loss of interest in life, communicative limitations, reduction of total activity.

The analysis of the research results showed that the use of various means of correcting codependent personality states should take into account the systemic approach, because the main drawback of a number of existing correctional approaches is the fact that they work on only one component of codependency sphere of personality. The existing means of correction of codependent personality states are not able to fully actualize the personal potential of codependent wives, whose husbands have alcohol problems. Thereby, it is necessary to focus not on a particular theoretical direction, but on the personal level characteristics of a codependent, and individualize the use of psycho funds.

In the process of theoretical and practical development of the problem, the basic principles of psycho-pedagogical correction approaches have been formulated, the necessity of using a number of means influencing the dynamics of codependent personality states has been justified. The choice of specific tools to work with codependent personality states has been tested in the psychological and social centers. As a result of the empirical study verbal (social-psychological training, the method of "social drama", "family photo") and nonverbal (family sculpture, family choreography, role-playing card game) means of psychological correction codependency have been identified.

The psychological correction of codependency also includes:

- Timely psychological and pedagogical impact, providing the optimum level of integrative capabilities of an individual.
- Adequate integrated system of psych correction, which allows to provide dynamic of codependent personality states.

- Development and implementation of the system necessary for a codependent persons to get rid of codependent conditions of personality.

The complex program of correction of the codependent personality states was elaborated and conducted during the experiment, taking into account the received data. The program allows reducing the level of psycho-emotional tension, to develop the ability to self-regulate behavior and it contributes to enhancing the overall activity of codependent women. We also tested a number of hypotheses containing assumptions about the significance of differences in the state of the studied variables belonging to the objects of different sets. Having carried out statistical processing of data using the Student's t-test and the Spearman correlation analysis, we obtained the following results;

1) A high level of codependent personality states with the personal characteristics of women were found. When testing in the middle and older age groups, it was found that a high level of codependent personality states is often detected in the women with high rates according to the following IRD test scales: increased guilt, complete dependence, excitability. The interrelation between the high level of code dependency and high rates on the ITQ scales of "anxiety, sthenichnost and labiality" has been noted.

2) The relationship between indicators of reducing the level of codependent personality states (anxiety, fear, impulsivity, self-centeredness, stubbornness, shame, guilt, hatred, depression, self-destructive behavior, etc.) and verbal and non-verbal means has been revealed.

A significant change in the level of codependency in the experimental group, compared with the control. This confirms our hypothesis about the possibility of the effective use of psychological means to correct the codependent personality states.

\section{REFERENCES}

[1] Arguelles, Jose. 1987. The May a Factor. Santa Fe: Bear \& Co.

[2] American Psychiatric Association. Diagnostic and statistical manual of mental disorders, Fifth Edition. Washington, DC: APA, 2013.

[3] Beattie M. 1997 The alcoholic in the family, or to overcome codependency. $\mathrm{M}$.

[4] Beattie, Melody. 1987. Co-dependent No More. New York: Harper \& Row.

[5] Black, Claudia. 1981. It Will Never Happen to Me. Denver, CO: M.A.C. Printing and Publication Division. 
[6] Dear G.E., \&. Roberts C.M. 2000.The Holyoake Codependency Index: Investigation of the factor structure and psychometric properties. Psychological Reports, Vol. 87, 991-1002.

[7] Fingarette, Herbert. 1988. Heavy Drinking: The Myth of Alcoholism as a Disease. Berkeley, CA: University of California Press.

[8] Griffin, Susan. 1978. Woman and Nature. New York: Harper \& Row.

[9] Halpern, Howard. 1982. How to Break Your Addiction to A Person. New York: McGraw-Hil Book Company.

[10] Kaplan, Louise J. 1978. Oneness and Separateness: From Infant to Individual. New York: Simon and Schuster.

[11] Karpman, Steven. 1968. "Fairytales and Script Drama Analysis”, Transitional Analysis Bulletin. 7:39-43.

[12] Miller, Alice. 1983. For Your Own Good. New York: Farrar, Straus, Giroux.

[13] Schaef, Anne Wilson. 1986. Co-Dependence Misunderstood-Mistreated. New York: Harper \& Row.

[14] Schiff, Jacqui, et al. 1975. The Cathexis Reader. New York: Harper \& Row.

[15] Subby, Robert. 1984. "Inside the Chemically Dependent Marriage: Denial Manipulation”, in Co-Dependency: An Emerging Issue. Pompano Beach, FL: Health Communications.

[16] Korolenko C. S, Dmitrieva N. V 2010. .Sotsiometricheskaya psychiatry. - New York: Academic Project, Yekaterinburg: Business Book.

[17] Korolenko TS. P., Dmitrieva NV, Zagoruiko. 2017 EN Identity. Novosibirsk, 472s.

[18] Moskalenko. V. D. 1992 The social work with families of alcoholics. Moscow.

[19] Moskalenko. V. D. 2014 Addiction. Familial disease. Moscow.

[20] Miroshnichenko, LD Addiction encyclopedia in two parts. M., 2001.

[21] Ruehling P. V., Koelbe N. l, \& Rutgers C. 1996. Codependence and conduct disorder: Feminine and masculine coping responses to abusive parenting practices. Sex Roles, Vol. 35, 603-618.

[22] Cloud, G., J. When Taundsen say YES. When to say NO. Spb., 1999.

[23] Young E Co alcoholism as a disease implication for psychotherapy / J Psychoactive Drugs - 987-Vol 19 N3-P 257

[24] Jakubczyk, A., Klimkiewicz, A., Wnorowska, A., Mika, K., Bugaj, M., Podgorska, A., Barry K., Blow, F.C., Brower, K.J., and Wojnar, M., 2013, Impulsivity, risk behaviors and accidents in alcohol-dependent patients., Accident Analysis and Prevention, 51, 150-155.

[25] Tomchuk N. V. Theoretical analysis of the codependence problems // Young scientist. - 2018. - №48. - P.260-262. URL http://moluch.ru/archive/234/54321/ 